\title{
Plant Growth in Plastic, Peat, and Processed Poultry Feather Fiber Growing Containers
}

\author{
Michael R. Evans ${ }^{1}$ and David L. Hensley ${ }^{2}$ \\ Department of Horticulture, University of Arkansas, Fayetteville, AR 72701
}

Additional index words. bedding plants, pots, paper pots, shoot weight

\begin{abstract}
A biodegradable container made from processed waste poultry feathers was developed, and plant growth was evaluated in plastic, peat, and feather containers. Under uniform irrigation and fertilization, dry shoot weights of 'Janie Bright Yellow' marigold (Tagetes patula L.), 'Cooler Blush' vinca [Catharanthus roseus (L.) G. Don.] and 'Orbit Cardinal' geranium (Pelargonium $\times$ hortorum L.H. Bailey) plants grown in feather containers were higher than for those grown in peat containers, but lower than those grown in plastic containers. Container type did not significantly affect dry shoot weights of 'Dazzler Rose Star' impatiens (Impatiens walleriana Hook.f.). 'Better Boy' tomato (Lycopersicum esculentum L.) dry shoot weights were similar when grown in peat and feather containers. Feather containers were initially hydrophobic, and several irrigation cycles were required before the feather container walls absorbed water. If allowed to dry, feather containers again became hydrophobic and required several irrigations to reabsorb water from the substrate. Peat containers readily absorbed water from the substrate. Substrate in peat containers dried more rapidly than the substrate in feather containers. Plants grown in peat containers often reached the point of incipient wilting between irrigations, whereas plants grown in feather containers did not. This may have been a factor that resulted in higher dry shoot weights of plants grown in feather containers than in peat containers. Tomato plants grown in feather containers had higher tissue $\mathbf{N}$ content than those grown in plastic or peat containers. The availability of additional $\mathrm{N}$ from the feather container may also have been a factor that resulted in higher dry shoot weights of plants grown in feather containers than in peat ones. Under non-uniform irrigation and fertilization, dry shoot weights of impatiens and vinca grown in feather containers were significantly higher than those of plants grown in plastic or peat containers. When grown under simulated field conditions, geranium dry shoot weights were significantly higher for plants initially grown in feather containers than for those initially grown in peat containers. Container type did not significantly affect dry shoot weights of vinca when grown under simulated field conditions. As roots readily penetrated the walls of both feather and peat containers, dry root weights of vinca and geranium were not significantly affected by container type when grown under simulated field conditions.
\end{abstract}

Containerized greenhouse and nursery crops are typically grown in plastic containers of varying sizes and shapes, depending upon the crop and targeted market. Although plastic containers are economically compatible with horticultural uses, strong, and can be formed to essentially any size, shape, and color, they have two significant limitations. Roots in plastic containers tend to circle the outer perimeter of the root ball once contact is made with the container. After transplanting into the field, roots continue to circle the root ball and can result in reduced growth and survival of plants in the field (Appleton, 1993; Struve, 1993). Plastic containers also present a significant disposal issue for the horticulture industry. The disposal of used plastic containers is particularly acute in the annual and perennial bedding plant markets, where relatively small plants are produced in

Received for publication 7 Jan. 2003. Accepted for publication 19 June 2003. This project was supported by Tyson Foods, Springdale, Ark., and the Arkansas Agricultural Research and Extension Service.

${ }^{1}$ Associate professor.

${ }^{2}$ Professor. large quantities. Commercial producers may encounter disposal issues particularly if plant materials are not sold during a season, since containers used to grow annual and perennial bedding plants are generally not reusable. Consumers and landscapers must remove plants from the plastic containers and are likewise left with containers for disposal.

Numerous attempts have been made to produce biodegradable containers that can be planted directly into the soil, thus reducing transplant shock and eliminating the need for disposal of used containers (Gayed, 1971; Lahde and Kinnunen, 1974; Mrazek, 1986). Typically, these containers have been made of peat, paper, or coir fiber. The most common nonplastic biodegradable container has been the peat container. Although referred to as peat containers, they are typically made from a combination of peat and waste wood pulp or paper. However, peat containers have significant disadvantages compared to plastic containers. Peat containers are more expensive than plastic containers and break or tear easily when wet. Plants grown in peat containers require more water than plants grown in plastic containers, and algae grows on the outside walls of the peat containers. When planted into the field, peat containers tend to "wick" water from the soil. Because this wicking allows the peat container wall to dry, the container can act as a significant impediment to root growth under conditions where the soil and container are allowed to dry between irrigations. Additionally, although biodegradable, the peat containers decompose very slowly and often must be removed from the soil when the planting areas are replanted.

Poultry feathers are a significant waste material produced by the meat-processing industry. Depending upon location, feathers may be dried and ground for use in fertilizers, such as feather meal (Choi and Nelson, 1996a, 1996b; Hadas and Kautsky, 1994), animal feeds (Brown and Pate, 1997; Moritz and Latshaw, 2001; Palmquist et al., 1993), burned, or landfilled. Feathers are made almost entirely of the scleroprotein keratin, are strong, biodegradable, and contain $\approx 15 \%$ organic $\mathrm{N}$ by weight (Hadas and Kautsky, 1994).

In cooperation with Tyson Foods (Springdale, Ark.), we developed a biodegradable container made primarily from processed waste poultry feathers. Our objective in this research was to evaluate plant growth in plastic, peat, and feather containers.

\section{Materials and Methods}

Experiment 1. Growth of plants in plastic, peat, and feather containers under uniform fertilization and irrigation. Plastic containers [Dura-Pot\#350-S (Hummert International, St. Louis)] were made of vacuum-formed black plastic. Plastic containers were $8.2 \mathrm{~cm}$ tall, with top and bottom widths of $8.2 \mathrm{~cm}$ and a volume of $370 \mathrm{~mL}$. Peat containers (Jiffy Group International, Kristiansand, Norway ) were 8.2 $\mathrm{cm}$ tall and had top and bottom widths of 8.0 and $5.2 \mathrm{~cm}$, respectively, and a volume of 335 $\mathrm{mL}$. Although referred to as peat containers, these containers were made of a combination of peat and wood pulp. The feather container design and composition were selected from 12 formulations evaluated prior to selection of the final test product for this study. The feather container (Tyson Foods) was composed of $85 \%$ processed feather fiber and $15 \%$ kraft paper. Feather containers were $8.3 \mathrm{~cm}$ tall, had top and bottom widths of 8.1 and $5.5 \mathrm{~cm}$, respectively, and a volume of $350 \mathrm{~mL}$.

Three-week-old 'Better Boy' tomato and 'Janie Bright Yellow' marigold and 4-week-old 'Dazzler Rose Star' impatiens, 'Cooler Blush' vinca, and 'Orbit Cardinal' geranium plugs (seedlings in size 288 plug trays with volume of $5 \mathrm{~mL}$ ) were transplanted into the plastic, peat, and feather containers filled with 330 $\mathrm{mL}$ of sphagnum peat, composted bark, and perlite-based SB-300 growing media (SunGro Horticulture, Bellevue, Wash.).

Plants were placed in a glass-glazed greenhouse, and the substrate was drenched with $50 \mathrm{~mL}$ of $15 \%$ etridiazole and $25 \%$ thiophanate-methyl (Banrot; Scotts, Marysville, Ohio) fungicide according to label directions. The minimum temperature set point for greenhouse air temperature was $20^{\circ} \mathrm{C}$ with a daytime high 
temperature of $28{ }^{\circ} \mathrm{C}$ during the experiment. Plants were grown under ambient light levels (300-380 $\mu \mathrm{mol} \cdot \mathrm{s}^{-1} \cdot \mathrm{m}^{-2}$ photosynthetic photon flux at $1200 \mathrm{HR}$ ) and fertilized at each irrigation with $200 \mathrm{mg} \cdot \mathrm{L}^{-1} \mathrm{~N}$ using a $15 \mathrm{~N}-2.2 \mathrm{P}-12.5 \mathrm{~K}$ fertilizer (Excel 15-5-15 Cal Mag; Scotts). Plants were irrigated when the substrate surface of $\approx 25 \%$ of all containers, regardless of container type, was visually determined to be dry, and when irrigation was conducted, all experimental units were irrigated. Therefore, in this experiment, all containers received the same number of irrigations and the same fertilization regime. However, depending upon container, some plants were watered more often than required, while some plants periodically reached the point of incipient wilting before being watered.

The experimental design was a randomized complete block with 10 blocks and each container type appearing once in a block. Container type served as the main treatment effect and each container was considered to be an independent experimental unit. After 3 weeks for tomato, 5 weeks for marigold and 8 weeks for impatiens, geranium, and vinca, the experiment was terminated. Shoot dry weights were determined. The experiment was conducted twice (blocked across time). No significant differences occurred across time, so the data were pooled across time. An analysis of variance (ANOVA) was conducted to determine if significant differences occurred among the container types. Where significant differences occurred, an LSD mean separation test was conducted to determine individual differences between means.

Leaves and stems of tomato plants from each container type were collected from the first experiment, ashed, and analyzed for total $\mathrm{N}$ according to methods outlined by the Southern State Cooperative Research Service (1992). For each container type, three replications were conducted with a replication consisting of two whole plants. An ANOVA was conducted to determine if significant differences occurred in shoot $\mathrm{N}$ concentration among the container types. Where significant differences occurred, an LSD mean separation test was conducted to determine individual differences between means.

Experiment 2. Growth of plants in plastic, peat, and feather containers undernon-uniform fertilization and irrigation. All experimental protocol were as described for experiment one except where indicated. 'Dazzler Rose Star' impatiens and 'Cooler Blush' vinca were included as test species in this experiment. Plants were irrigated with $200 \mathrm{~mL}$ of fertilizer solution when the substrate surface began to dry as determined visually. Each container was irrigated individually as required. Therefore in this experiment, different containers received varying amounts of water and mineral elements depending upon the rate at which the substrate dried. However, none of the plants were allowed to reach the point of incipient wilting before being watered. The experimental design was a randomized complete block with eight blocks and each container type appearing once in a block.
Experiment 3. Shoot and root growth of plants grown in plastic, peat, and feather containers and planted into simulated field conditions. All experimental protocol were as described for Expt. 1, except where indicated. 'Dazzler Rose Star' impatiens and 'Cooler Blush' vinca were grown in plastic, peat, and feather containers as described under Expt. 2. Six weeks after plugs were transplanted into the test containers, the plants were potted into $4-\mathrm{L}$ round black plastic containers $(19.4 \mathrm{~cm}$ diameter and $17.5 \mathrm{~cm}$ tall) filled with SB-300 substrate. Plastic containers were removed prior to planting. Peat and feather containers were left intact and planted with $\approx 1 \mathrm{~cm}$ of the container rim above the substrate level. The minimum temperature set point for greenhouse air temperature was $20^{\circ} \mathrm{C}$ with a daytime high temperature of $35^{\circ} \mathrm{C}$ during the experiment. Plants were grown under ambient light levels (300-540 $\mu \mathrm{mol} \cdot \mathrm{s}^{-1} \cdot \mathrm{m}^{-2}$ photosynthetic photon flux at $1200 \mathrm{HR}$ ) After 12 weeks, shoot and root dry weights were determined. The experimental design was a randomized complete block with six blocks and each container type appearing once in a block.

\section{Results and Discussion}

Experiment 1. Growth of plants in plastic, paper, and feather containers under uniform fertilization and irrigation. Dry shoot weights of marigold, vinca, and geranium were significantly higher for plants grown in plastic containers than for plants grown in peat or feather containers (Table 1). Dry shoot weights of marigold, vinca, and geranium plants grown in feather containers were higher than for plants grown in peat containers. There was no significant difference in dry shoot weights among impatiens grown in the three container types. Dry shoot weights of tomato plants grown in plastic containers were significantly higher than dry shoot weights of tomato plants grown in either peat or feather containers. Dry shoot weights of tomato were not significantly different between plants grown in peat and feather containers. Block significantly affected dry shoot weights of impatiens, vinca, and geranium but did not significantly affect dry shoot weights of tomato and marigold.

For all species except impatiens, dry shoot weights were higher in plastic containers than in peat ones. An important difference between plastic and peat containers was that the substrate in peat containers dried at a faster rate than that in plastic ones. Because plants were watered only after $\approx 25 \%$ of all containers displayed surface drying of the growing medium, plants in peat containers periodically reached the point of incipient wilting between irrigations. This mild water stress may have resulted in reduced growth and reduced dry shoot weights of plants grown in peat containers as compared to those grown in plastic containers.

For marigold, vinca, and geranium, dry shoot weights were higher in feather containers than in peat ones. Substrates in feather containers dried more slowly, and plants grown in feather containers reached the point of incipient wilting less often than plants grown in peat containers. Feather containers were initially hydrophobic. Several irrigation cycles were required to soften the feather containers and allow the container walls to absorb water. If allowed to dry, feather containers tended to be hydrophobic and required time to reabsorb water from the substrate. Peat containers readily absorbed water from the substrate. Therefore, feather containers allowed less evaporation through the surface of the container wall than peat containers, and substrate in the feather containers lost water more slowly than substrate in peat ones.

An additional factor that may have resulted in higher dry shoot weights of certain plant species grown in feather vs. peat containers may have been $\mathrm{N}$ availability. Ground feathers used to make these containers are typically $15 \%$ organic $\mathrm{N}$ by weight. Therefore, feather containers would have contained $\approx 13 \%$ organic $\mathrm{N}$ by weight. Plant roots readily grew into the container walls of feather containers. Additional $\mathrm{N}$, other than that supplied in the fertilization program, may have been available to plants growing in feather containers. Average tissue $\mathrm{N}$ level of tomato plants grown in feather containers was $3.3 \%$ and was significantly higher than that of tomato plants grown in peat and plastic containers, which was $1.5 \%$ and $1.6 \%$, respectively. Certain species, such as tomato and geranium, typically had visually darker green foliage when grown in feather containers than when grown in peat or plastic containers. Therefore, in addition to differences in water relations of plants grown in peat and feather containers, nutritional differences occurred due

Table 1. Dry shoot weights (g) of ornamental species grown in plastic, peat, and feather containers under uniform irrigation and fertilization.

\begin{tabular}{lccccc}
\hline & \multicolumn{5}{c}{ Species } \\
\cline { 2 - 6 } Container $^{2}$ & Marigold & Vinca & Geranium & Impatiens & Tomato \\
\hline Plastic & 3.9 & 4.6 & 8.2 & 2.9 & 10.6 \\
Peat & 2.4 & 1.9 & 5.5 & 2.6 & 6.5 \\
Feather & 3.0 & 2.5 & 6.4 & 2.9 & 7.2 \\
Significance & & & & & $* * *$ \\
$\quad$ Container & $* * *$ & $* * *$ & $* * *$ & $*$ & NS \\
$\quad$ Block & NS & $*$ & $* *$ & $* *$ & 0.9 \\
$\quad$ LSD $(\alpha=0.05)$ & 0.4 & 0.4 & 0.7 & 0.3 & \\
\hline
\end{tabular}

${ }^{2}$ Plastic containers were vacuum-formed Dura-Pot\#350-S (Hummert International, St. Louis); peat containers were compressed peat and paper pulp (Jiffy Group International, Kristiansand, Norway); and feather containers (Tyson Foods, Springdale, Ark.) were composed of $85 \%$ processed feather fiber and $15 \%$ kraft paper.

Ns, ,********Nonsignificant or significant at $P=0.05,0.01$, or 0.001 , respectively. 
Table 2. Dry shoot weights ( $g$ ) of impatiens and vinca grown in plastic, peat, and feather containers under non-uniform irrigation and fertilization.

\begin{tabular}{lcc}
\hline Container $^{z}$ & Impatiens & Vinca \\
\hline Plastic & 5.1 & 5.3 \\
Peat & 5.0 & 5.2 \\
Feather & 6.1 & 6.5 \\
Significance & & \\
$\quad$ Container & $* * *$ & $* * *$ \\
$\quad$ Block & NS & NS \\
$\quad$ LSD $(\alpha=0.05)$ & 0.7 & 0.8 \\
\hline
\end{tabular}

${ }^{2}$ Plastic containers were vacuum-formed Dura-Pot \#350-S (Hummert International, St. Louis); peat containers were compressed peat and paper pulp (Jiffy Group International, Kristiansand, Norway); and feather containers (Tyson Foods, Springdale, Ark.) were composed of $85 \%$ processed feather fiber and $15 \%$ kraft paper.

$7_{\text {rт,**** Nonsignificant or significant at } P=0.001}$

to the composition of the containers. Different plant species have different nutritional requirements and respond differently to changes in $\mathrm{N}$ fertility levels (Dole and Wilkins, 1999). Although the increased availability of $\mathrm{N}$ did not result in significant increases in dry shoot weight in impatiens and tomato, it may have contributed to the increased dry shoot weight of marigold, vinca, and geranium.

Except for impatiens, where no significant difference in dry shoot weights occurred between plants grown in feather and plastic containers, plants grown in plastic containers had higher dry shoot weights than those grown in feather ones. In this case, the difference in water availability due to differences in drying rates between plastic and feather containers had a greater effect on plant growth than $\mathrm{N}$ availability.

This experiment was blocked against a known temperature gradient and variation in air movement caused by horizontal air-flow fans. These gradients resulted in uneven evapotranspiration among the blocks and introduced variation. This resulted in a significant block effect for impatiens, vinca, and geranium. The variation between blocks for tomato and marigold was nonsignificant. The later two species required only 4 weeks of growth before data were taken. The former three species required 8 weeks. Thus, the longer production time allowed for the environmental differences to have a greater impact on dry shoot weights.

Experiment 2. Growth of plants in plastic, paper, and feather containers under non-uniform fertilization and irrigation. Dry shoot weights of impatiens and vinca plants grown in feather containers were significantly higher than those of plants grown in plastic or peat containers (Table 2). Dry shoot weights were not significantly different among impatiens and vinca plants grown in plastic and peat containers. The results of this experiment differed from the results of Expt. 1, in which plants grown in plastic containers had higher dry shoot weights than plants grown in feather containers. In this experiment, all plants were irrigated as needed. Therefore, no plants reached the point of incipient wilting and, thus, the potential effect of

Table 3. Growth of geranium and vinca grown in plastic, peat and feather containers when planted in simulated field conditions.

\begin{tabular}{|c|c|c|c|c|}
\hline \multirow[b]{2}{*}{ Container $^{2}$} & \multicolumn{2}{|c|}{ Geranium } & \multicolumn{2}{|c|}{ Vinca } \\
\hline & Dry shoot wt (g) & Dry root wt $(\mathrm{g})$ & Dry shoot wt (g) & Dry root wt (g) \\
\hline Plastic & 38.5 & 2.8 & 95.3 & 5.4 \\
\hline Peat & 37.3 & 2.4 & 84.5 & 5.2 \\
\hline Feather & 41.9 & 2.5 & 89.4 & 6.7 \\
\hline Significance & & & & \\
\hline Container & $*$ & NS & NS & NS \\
\hline Block & $*$ & NS & NS & NS \\
\hline $\operatorname{LSD}(\alpha=0.05)$ & 3.5 & --- & --- & --- \\
\hline
\end{tabular}

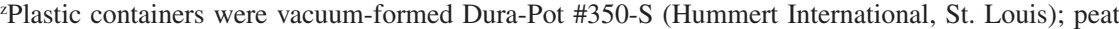
containers were compressed peat and paper pulp (Jiffy Group International, Kristiansand, Norway); and feather containers (Tyson Foods, Springdale, Ark.) were composed of $85 \%$ processed feather fiber and $15 \%$ kraft paper.

Ns, ${ }^{* * *}$ Nonsignificant or significant at $P=0.05$.

mild water stress was removed. However, as in Expt. 1, plants grown in feather containers were able to obtain additional nitrogen from the container walls; this may have contributed to the higher dry shoot weights of plants grown in feather containers. Further, when the difference in water availability was removed as a factor, plants in plastic and peat containers had similar dry shoot weights. This supported the contention that the primary factor resulting in plastic having significantly higher dry shoot weights under uniform irrigation (Expt. 1) was water availability. When the effect of mild water stress was removed, $\mathrm{N}$ availability had a greater effect and contributed to plants grown in feather containers having significantly higher dry shoot weights than plants grown in plastic and peat. Additionally, dry shoot weights were generally higher for impatiens and vinca in the second experiment than in the first. This may have occurred because only $\approx 25 \%$ of the plants in the first experiment were watered as required, while others suffered mild water stress or were overwatered.

Experiment 3. Shoot and root growth of plants grown in plastic, peat, and feather containers and planted into simulated field conditions. Geranium plants grown in feather containers and transplanted into simulated field conditions had significantly higher dry shoot weights than those grown in peat containers (Table 3). Geranium dry shoot weights were not significantly different between plants grown in plastic or peat containers. Geranium dry root weights were not significantly different among the container types. Neither dry shoot weights of geranium nor dry root weights of vinca were significantly affected by container type.

Root growth of geranium and vinca was not inhibited by the container walls of either peat or feather containers. Plants grown in feather containers and transplanted into simulated field conditions had dry root and shoot weights similar to those grown in plastic containers that were removed prior to planting. Geranium grown in feather containers had higher dry shoot weights than those grown in peat containers. This result may have been an artifact or the result of additional $\mathrm{N}$ being available from the feather container. Regardless, feather containers could be planted directly into the field, did not impede plant growth, and plants in feather containers performed as well in the simulated field conditions as plants grown in plastic and peat containers.

\section{Literature Cited}

Appleton, B.L. 1993. Using copper compounds to modify roots on container-grown trees. Combined Proc. Intl. Plant Propagators Soc. 43:376-379.

Brown, W.F. and F.M. Pate. 1997. Cottonseed meal or feather meal supplementation of ammoniated tropical grass hay for yearly cattle. J. Animal Sci. 75:1666-1673.

Choi, J.M. and P.V. Nelson. 1996a. Developing a slow-release nitrogen fertilizer from organic sources. II. Using poultry feathers. J. Amer. Soc. Hort. Sci. 121:634-638.

Choi, J.M. and P.V. Nelson. 1996b. Developing a slow-release nitrogen fertilizer from organic sources. III. Isolation and action of a featherdegrading actinomycete. J. Amer. Soc. Hort. Sci. 121:639-643.

Dole, J.M. and H.F. Wilkins. 1999. Floriculture principles and species. Prentice Hall, Upper Saddle River, N.J.

Gayed, S.K. 1971. Effect of transplanting tobacco seedlings in peat pots on plant vigor and on susceptibility to Thielaviopsis root rot. Can. Plant Dis. Survey 51(4):142-144.

Hadas, A. and L. Kautsky. 1994. Feather meal, a semi-slow-release nitrogen fertilizer for organic farming. Fert. Res. 38(2):165-170.

Lahde, E. and K. Kinnunen. 1974. The relationship between wall strength of paper and peat pots and the initial development of seedlings in northern Finland. Folia Forestalia 197:1-19.

Moritz, J.S. and J.D. Latshaw. 2001. Indicators of nutritional value of hydrolyzed feather meal. Poultry Sci. 80(1):79-86.

Mrazek, F. 1986. Comparative growth studies of plants in peat pots and with naked roots in an advanced plantation of douglas firs. Beitr. Forstwirtschaft 20(3):128-129.

Palmquist, D.M., M.R. Weisbjerg, and T. Hvelplund. 1993. Ruminal, intestinal and total disgestibilities of nutrients in cows fed diets high in fat and undegradable protein. J. Dairy Sci. 76:1353-1364.

Southern Cooperative Research Service. 1992. Plant analysis reference procedures for the southern region of the United States. Bul. 368.

Struve, D.K. 1993. Effect of copper-treated containers on transplant survival and regrowth of four tree species. J. Environ. Hort. 11:196-199. 